\title{
PROFESSORES INICIANTES E SUA INSERÇÃO NO ESPAÇO ESCOLAR: A CONSTRUÇÃO DA IDENTIDADE PROFISSIONAL
}

\author{
BEGINNING TEACHERS AND THEIR INSERTION IN \\ THE SCHOOL SPACE: A CONSTRUCTION \\ OF THE PROFESSIONAL IDENTITY
}

\author{
PROFESORES INICIANTES Y SU INSERCIÓN EN EL \\ ESPACIO ESCOLAR: LA CONSTRUCCIÓN DE \\ LA IDENTIDAD PROFESIONAL
}

\section{TÂnia Cristina Silva Pessoa \\ Raimunda ABou GeBran}

Universidade do Oeste Paulista/UNOESTE/ Presidente Prudente

\begin{abstract}
Resumo A formação e a atuação de professores têm uma trajetória construída historicamente e marcada por características que estarão presentes na construção de sua identidade profissional. O objetivo deste estudo foi identificar e analisar a construção da identidade docente a partir do olhar do professor iniciante no momento de sua inserção na carreira, bem como, compreender os conflitos e dificuldades desse processo. Configurou-se como pesquisa qualitativa do tipo descritivo-interpretativo e para a coleta de dados foi aplicado questionário e realizada entrevista semiestruturada com oito docentes iniciantes. Os resultados revelaram que os professores, ao analisar os limites da sua formação inicial, sofrem o "choque com a realidade"; desejam aprimorar o seu trabalho para a construção de sua identidade profissional e entendem a formação continuada como necessária para a profissão. $\mathrm{O}$ estudo poderá suscitar discussões e reflexões sobre políticas de apoio ao professor iniciante e processos de formação de professores.
\end{abstract}

Palavras-chave: Professor Iniciante; Identidade Docente; Ensino Fundamental; InserÇÃo EsCOLAR. 
Abstract The training and performance of teachers has a history built historically marked by features that will be present in the construction of professional identity. The aim of this study was to analyze and identify the construction of teacher identity from the view of the beginning teacher at the time of his insertion in the career, as well as understand the conflicts and difficulties of this process. It was set up as a qualitative research of the descriptive-interpretative type and for data collection a questionnaire was applied and a semi-structured interview was carried out with 8 (eight) beginning teachers. The results revealed that teachers analyze the limits of their initial formation, suffer the "shock with reality"; Wish to improve their work to build their professional identity and understand continuing education as necessary for the profession. The study may lead to discussions and reflections on policies to support beginning teacher and teacher training processes.

Key-words: Beginner Teacher; Teacher Identity; Elementary School; School insertion.

RESUMEN La formación y la actuación de profesores tienen una trayectoria construida históricamente y marcada por características que estarán presentes en la construcción de su identidad profesional. El objetivo de este estudio fue identificar y analizar la construcción de la identidad docente a partir de la mirada del profesor principiante en el momento de su inserción en la carrera, así como, comprender los conflictos y dificultades de ese proceso. Se configuró como investigación cualitativa del tipo descriptivo-interpretativo y para la recolección de datos fue aplicado cuestionario y realizada entrevista semiestructurada con ocho docentes principiantes. Los resultados revelaron que los profesores, al analizar los límites de su formación inicial, sufren el "choque con la realidad"; desean perfeccionar su trabajo para la construcción de su identidad profesional y entienden la formación continuada como necesaria para la profesión. El estudio podrá suscitar discusiones y reflexiones sobre políticas de apoyo al profesor principiante y procesos de formación de profesores.

Palabras clave: Profesor principiante; Identidad Docente; Enseñanza fundamental; InSERCIÓN ESCOLAR.

\section{INTRODUÇÃo}

O presente trabalho busca considerar que o professor iniciante se depara com situações complexas no seu cotidiano escolar, vivenciando uma realidade incerta, no que se refere ao que, de fato, poderia encontrar no momento de inserção no espaço escolar. As inquietações e as angústias, por exemplo, são frutos de um acúmulo de situações iniciadas a partir da sua inexperiência. É fato que o processo da construção da identidade docente se confronta com o medo de ser professor. Dessa maneira, a pesquisa permitiu o levantamento de algumas questões norteadoras, sendo elas: Como se dá a inserção dos profissionais docentes iniciantes nas instituições de Ensino Fundamental? Que ações formativas a escola e a Rede de Ensino Municipal oferecem para a melhoria da construção dos saberes desses profissionais no momento de sua inserção profissional? Há políticas de apoio para novos 
professores, dentro e fora do contexto escolar? Como é realizada a troca de saberes e/ou a relação do iniciante com professores mais experientes na escola e vice-versa? Quais possíveis deficiências de formação esses profissionais possuem ao se inserir na profissão?

Mediante tais questionamentos, o estudo teve por objetivo analisar e identificar a construção da identidade docente a partir do olhar do professor iniciante, mais precisamente sobre sua inserção na carreira, bem como compreender os conflitos e dificuldades no processo de iniciação à docência.

O estudo foi realizado com oito docentes iniciantes (de um a três anos de exercício no magistério) de escolas da Rede Municipal de Ensino Fundamental I do município de Rancharia, no Estado de São Paulo, que atendiam crianças com idade de 6 a 10 anos, contratados por meio de processo de seleção por tempo determinado e não por concurso público.

Para o desenvolvimento da pesquisa, optou-se por uma abordagem qualitativa de caráter descritivo-interpretativo (GIL, 2007, GARCEZ, 2010). A coleta de dados centrou-se na aplicação de questionário com questões objetivas que permitiram traçar o perfil pessoal e profissional dos participantes e entrevistas com roteiro semiestruturado.

O trabalho apresenta uma fundamentação teórica por meio da revisão de literatura abordando o professor iniciante, a sua inserção na carreira docente e o processo da construção da sua identidade profissional. No delineamento metodológico, destacam-se a tipologia da pesquisa assumida, os critérios para a seleção dos participantes da pesquisa; os procedimentos para a coleta e análise dos dados. A discussão e análise dos dados centraram-se em categorias que emergiram do material coletado. Nas considerações finais, apontamos alguns indicativos que poderão suscitar discussões e reflexões sobre políticas de apoio ao professor iniciante e processos de formação de professores, bem como, propostas para futuros estudos sobre a temática.

\section{REFLETINDO SOBRE A INSERÇÃO NA CARREIRA DOCENTE}

Com o intuito de se iniciar esta discussão sobre o momento de inserção na carreira docente, não se pode deixar de enfatizar a figura do professor iniciante e destacar as novidades, as surpresas e as dificuldades que esse profissional encontra no início de sua carreira. Sobre isso, Lotumolo (2014, p. 23) comenta que "a docência é uma profissão que se caracteriza por expectativas, desejos, medos e angústias, seja em qual for a situação que o professor se encontre".

Papi (2014) relata que a formação docente está inserida primeiramente no âmbito de formação humana e das relações sociais, e que esse processo se articula por meio da construção da vida em sociedade, marcado por rupturas e contradições. $\mathrm{O}$ ato de formar é complexo, pois exige diversos elementos constitutivos da formação que se estabelecem nas relações humanas, epistemológicas, sociais, cognitivas, entre outras. Assim, a realidade educacional também é complexa, com grandes diferenças, históricas, políticas e sociais, e a relação entre a teoria e a prática pedagógica na formação de professores precisa se atrelar 
a um processo de formação compatível com o contexto social, político e econômico (VEIGA, 2013).

Nesse sentido, Ferreira (2014, p. 40) acrescenta que:

Os conhecimentos adquiridos nos cursos de formação (inicial/continuada) precisam imprimir em seus discentes, características de uma formação que busque a teorização acadêmica, a criticidade, a reflexão sobre a prática, a pesquisa como possibilidade para novos conhecimentos que a docência enfrenta na contemporaneidade (FERREIRA, 2014, p. 40).

Portanto, ser professor na atualidade demanda enfrentar desafios colocados à carreira docente, como as angústias quanto à realidade social, a falta de formação continuada, as questões referentes à remuneração, a busca pela valorização social, entre outros. Esses elementos precisam ser considerados pelos formadores de professores, principalmente na preparação da entrada desses profissionais na carreira docente, pois a atuação docente é elemento relevante no processo de transformação social.

Mariano (2006) afirma que o início da profissão docente se relaciona com a trajetória escolar de cada docente inserido no contexto de sua individualidade. Isso pode subentender a ideia de que o futuro professor já saiba como desenvolver o trabalho dentro da escola e sala de aula, pois ele já passou pelos espaços escolares, anteriormente, como estudante. Porém, essas mudanças nos papéis, ou seja, de aluno para professor, trazem inesperadas situações nunca vividas e também muitas vezes pouco trabalhadas em sala de aula.

O período de entrada para a docência é marcado por situações inusitadas, pois o novato se depara com momentos que demandam ações urgentes em sua rotina de trabalho e com o objetivo de acertar, experimentando atitudes que, por vezes, não têm o êxito esperado. A respeito disto, Huberman (2013) relata que, na trajetória profissional de professores, existem diferentes etapas que estão presentes na vida pessoal e profissional, cada qual acontecendo em momentos distintos, influenciando a maneira como eles se veem, reconhecem o seu trabalho e delimitam sua identidade. Para o autor, a docência passa por etapas, durante as quais os professores têm necessidades formativas e que possuem conhecimentos e experiências diferentes. O autor (2013, p. 39) ainda traça um quadro-síntese das tendências gerais possíveis de identificar no ciclo de vida dos professores, descrevendo-as em fases que compõem a carreira do professor (entrada na carreira, estabilidade, diversificação ou questionamento, serenidade, conservantismo e lamentações e desinvestimento). Contudo, pondera que os ciclos devem ser vistos como um caminhar pela carreira e não uma série sucessiva de eventos pontuais, ou seja, docente algum se tornará um bom profissional na carreira rapidamente, mas por meio de experiências e vivências que proporcionem a relação teoria e prática, e não apenas por observação do outro, como muitas vezes lhe é apresentado no estágio supervisionado nos cursos de licenciatura.

É interessante ressaltar que esses ciclos citados por Huberman (2013), mais especificamente o ciclo inicial, trazem aos docentes recém-formados uma realidade que não é cotidianamente comentada no convívio universitário, por exemplo, a ambientação com os colegas 
de trabalho, a rotina do contexto escolar, sua apresentação à sala de aula, entre outros. Nesse novo ambiente, ao relacionar a sua experiência como discente para com suas atribuições, agora de docente, podem ocorrer desequilíbrios emocionais e, principalmente, profissionais.

Esse momento de apresentação do docente é comentado por Sacristán (1998), ao afirmar que o professor passa por um momento de transição, ou seja, da experiência passiva como aluno, para a ativa como professor, sem que lhe seja oferecido de forma plena o real significado educativo, social e epistemológico do conhecimento que desenvolve com os seus alunos.

O fato é que o ingresso na carreira docente aponta muitas dificuldades, pois o novo professor se depara com maiores responsabilidades e com necessidades de se desapegar de muitas imagens construídas quando fora aluno. Esses impasses se tornam complicados nos primeiros anos de carreira profissional, muitas vezes impedindo que ele venha desempenhar competentemente o seu trabalho docente. O docente iniciante, ao perceber que as exigências são mais abrangentes, vive o que Veenman (1984) e Tardif (2002) denominam como choque de realidade, ou seja, quando ele confronta as teorias vivenciadas no ambiente acadêmico com a prática, quer dizer, as dimensões representadas pelos diversos movimentos do espaço escolar.

Esse choque de realidade acontece devido a um desajustamento dos professores já no exercício da função, promovendo um distanciamento entre o significado e o alcance do seu trabalho e com isso tendem a vivenciar sentimentos de desânimos, desencantos, surpresas e tensões ao realizarem o trabalho docente. Essa fase crítica de choque, ou seja, o enfrentamento de questões que fazem refletir sobre a teoria e a prática no efetivo exercício docente, se (res)significa a todo instante.

Dessa forma, a construção da identidade docente está interligada à práxis profissional, considerando as mudanças que ocorrem e afetam as relações no processo de ensino e aprendizagem e de como o professor se vê em determinado momento histórico de sua carreira. Na visão de Santos (2012), é necessário acrescentar que a identidade do professor envolve características pessoais e profissionais, e que elas se constroem a partir das relações sociais que englobam o indivíduo, a instituição educacional, a família e os que influenciam de alguma maneira a estruturação do conhecimento.

Sendo assim, o processo de construção e (re)construção da identidade do professor se dá de maneira contínua, a partir de reflexões das suas experiências pessoais e profissionais que elaboram seus próprios saberes e conhecimentos e que vão direcioná-lo para a construção de uma autonomia intelectual e, por conseguinte, a construção de sua identidade (SANTOS, 2012).

Em suma, além de observar sua própria imagem e do seu trabalho, a identidade do professor também é constituída socialmente na relação dialética com os papéis e as representações sociais precedentes e com o grupo de trabalho, bem como, a autoavaliação diária do seu trabalho, pois essa é demonstrada pelos discentes no dia a dia, na participação das aulas, no cumprimento das atividades, na devolutiva dos gestores e, acima de tudo, com os pais e comunidade escolar. 


\section{Metodologia e Participantes da PesQuisa}

Para o desenvolvimento da pesquisa, optou-se por uma abordagem qualitativa de caráter descritivo-interpretativo. Segundo Gil (2007, p. 43), "uma pesquisa explicativa, interpretativa pode ser a continuação de outra descritiva, posto que a identificação de fatores que determinam um fenômeno exige que este esteja suficientemente descrito e detalhado".

Assim, por se pretender responder questões de natureza explicativa, do tipo "como" e "por que", procurou-se aprofundar na análise e compreensão das concepções e ações dos professores iniciantes, interpretando-as sem se preocupar com a representatividade numérica, generalizações estatísticas e relações lineares de causa e efeito (LÜDKE e ANDRÉ, 2013). Os procedimentos para a coleta de dados foram: 1) aplicação de questionário, composto por questões fechadas, que objetivaram delinear o perfil dos participantes, a trajetória e o percurso de formação de sua vida pessoal e 2) entrevista semiestruturada, que possibilitou o levantamento de informações e questionamentos quanto à escolha da profissão e o processo de inserção na docência, bem como avaliar o desempenho desses profissionais e as dificuldades encontradas nas práxis pedagógica.

O estudo foi realizado nas cinco escolas da Rede Municipal de Ensino Fundamental I do município de Rancharia, Estado de São Paulo, com um total de oito professores iniciantes e que se enquadravam no critério estabelecido, ou seja, aqueles profissionais que possuíam até três anos de experiência na docência.

\section{Resultados E Discussão}

\section{O perfil dos participantes}

Foi observado na pesquisa que $100 \%$ dos sujeitos são do sexo feminino, indicando a feminização na docência no Ensino Fundamental, o que, para Leoni (2011, p. 153), "transcende a questão numérica em direção à reflexão acerca de suas implicações na construção das representações sociais sobre a profissão docente e na consolidação do estatuto profissional da docência". Todas as participantes eram graduadas em instituições de Ensino Superior privado e o principal motivo de cursarem o ensino superior nesse tipo de instituição residiu no fato de que existem, no município do local da pesquisa, instituições privadas, o que facilitou o ingresso na graduação em virtude das parcerias firmadas com empresas. Somando-se a isso, nos últimos anos houve também a abertura de bolsas de estudo gratuitas oferecidas pelas esferas municipais, estaduais e federais, como: Programa Escola da Família, Prouni (Programa Universidade para Todos), SISU (Sistema de Seleção Unificada) e FIES (Fundo de Financiamento Estudantil), que favoreceram a grande inserção em cursos superiores.

\section{As revelações das falas}

Para melhor entendimento e organização dos dados coletados nas entrevistas, após as transcrições, buscou-se problematizar as ideias mais evidenciadas pelos sujeitos por meio 
de suas respostas, organizadas em eixos de análise que se relacionaram com os objetivos específicos da pesquisa.

\section{A escolha da docência}

Diante das circunstâncias do cenário atual em que a demanda pela escolha da carreira docente, especialmente na educação básica, tem decrescido e a atratividade pela docência passa por intranquilidade, compreender os motivos que levam a essa escolha profissional parece relevante para a análise sobre a inserção docente. Esses motivos podem permitir uma aproximação com as questões de satisfação ou insatisfação profissional influenciadoras na decisão de permanência ou não na carreira.

Fassina (2013) destaca que a atratividade da carreira docente e "estar professor" oscilam entre a satisfação e a frustração, entre a escolha e a necessidade, já que as pressões exercidas junto aos profissionais da educação têm gerado muitas inquietações, principalmente a respeito das responsabilidades atribuídas ao educador. Problematiza ainda sobre questões elementares para tal contexto, por exemplo, o salário e condições de trabalho para exercer a profissão.

Ao serem interrogadas sobre as razões pelas quais optaram à docência, as professoras explicitaram um conjunto de motivos, entre eles: a oferta do curso oferecida pela faculdade instalada na cidade e maior oportunidade de campo de trabalho e a escolha feita pelo desejo e sonho de se tornarem professoras. Em relação ao desejo de trabalhar com criança e ao sonho de se tornar professoras, seguem-se alguns relatos:

\footnotetext{
Eu sempre sonhei em ser professora desde criança. Porém no decorrer da minha vida tive que seguir outras profissões que não deram certo, então voltei para docência que é o que eu gosto de fazer. Sinto prazer em estar na sala de aula e trabalhar com crianças. (Cristina)
}

Sabia que queria ser professora e adoro trabalhar com as crianças, fiquei na dúvida em Letras e Pedagogia, como eu só tinha dezessete anos na época, optei por cursar Pedagogia, pois a minha cidade oferecia. (Priscila)

As falas mencionam o prazer de ensinar, como uma motivação para a docência. Nesse sentido, a especificidade do trabalho do professor se define pela ação de ensinar, "fazer que outros se apropriem de um saber", ou "fazer aprender alguma coisa a alguém", numa dimensão além da disciplinar (ROLDÃO, 2007). Outros relatos das docentes destacam a possibilidade de ensinar e transmitir conhecimento; o interesse por área específica do conhecimento; a identificação profissional; a possibilidade de formar e influenciar novas gerações; a possibilidade de trabalhar com crianças; a valorização das relações interpessoais; a realização pessoal (prazer, amor, desejo, gostar); a possibilidade de influenciar/ transformar a realidade social; a identificação pessoal; a influência familiar; a influência dos professores e as oportunidades no mercado de trabalho.

Quanto à oportunidade de trabalho, associada aos benefícios oferecidos pela profissão, não deixa de ser interessante, num contexto em que as questões relativas à profissio- 
nalização e às condições do exercício profissional vêm sendo debatidas e reivindicadas. Nesse sentido, é interessante destacar a resposta da professora Eduarda que registra que:

\begin{abstract}
A docência não foi a minha primeira opção, porém dentre os cursos oferecidos na minha cidade percebi que era o que eu teria mais oportunidade quanto ao campo de trabalho, então escolhi cursar pedagogia visando o salário. [...]. (Eduarda)
\end{abstract}

A escolha pela profissão não teria ocorrido como forma de realizar um projeto profissional previamente estabelecido, mas como uma alternativa viável dentro de sua realidade. Assim, para essa participante, ser professora foi uma escolha possível no início da vida profissional, corroborando Lapo e Bueno (2003), ao afirmarem que alguns profissionais docentes escolhem a profissão como o único meio de sobrevivência no contexto em que vivem. Nos relatos, verificou-se que a docência não foi a ocupação almejada, contudo, elas conseguiram estabelecer vínculos com a profissão, iniciando um processo de identificação e de busca por satisfação no trabalho docente.

Sobre as motivações para a escolha da profissão, pontuou-se ainda que as professoras buscaram elementos que as aproximassem da docência. Esses relatos indicaram que nem sempre a escolha pela docência ocorre anteriormente à formação inicial, mas pode transcorrer no processo formativo, o que revela a importância que ele assume na construção de sua identidade profissional. Na perspectiva de Bourdieu (1999), entende-se que, de modo geral, a escolha pela carreira docente não se deu de forma aleatória para esse grupo de professoras iniciantes, mas se configurou em um processo complexo, ambíguo e multifacetado, que envolve um conjunto de possibilidades e de impossibilidades profissionais, por exemplo, o envolvimento das questões sociais, culturais e, principalmente, nesse caso, pelas questões econômicas e financeiras.

Em resumo, os dados evidenciaram que a história de vida das professoras, as condições econômicas e sociais marcaram a escolha pela docência. Destacaram fatores intrínsecos e extrínsecos ao optarem pela docência e se entendeu que a escolha não se deu de forma aleatória, mas se constituiu num processo que envolveu determinações no contexto profissional e pessoal.

\title{
Inserção docente e o choque de realidade
}

No segundo eixo de análise procurou-se apontar e analisar as dificuldades, preocupações e sentimentos vivenciados pelas professoras no período da inserção profissional. Ao serem interrogadas sobre as principais dificuldades, elas revelaram o trabalho a ser desempenhado com a quantidade e diversidade de conteúdos e desenvolvê-los de forma satisfatória para a ocorrência da aprendizagem dos alunos, adequando-os aos diferentes níveis e estilos de aprendizagens e, em especial, em atender a heterogeneidade dos discentes. 
ficado... uma criança é diferente da outra...trabalhar diferente e montar uma aula de um tipo para um aluno e outra para outro aluno é muito difícil. (Eduarda)

As professoras indicaram, ainda, dificuldades relacionadas à quantidade e adequação do conteúdo e sentimentos de medo e insegurança que experimentaram nesse momento de inserção, como evidenciadas a seguir:

Outro desafio é sobre os conteúdos, e a quantidade estabelecida por bimestre, como estou iniciando sinto que não tenho a didática plena para aplicá-los, mas tenho que "dar conta", então fico confusa e não sei qual caminho seguir, ou seja, se cumpro os conteúdos e não me importo se a crianças aprenderam ou não? Ou se eu foco nas crianças quanto a sua aprendizagem e esqueço dessa "cobrança" de conteúdo? Eu fico com "medo" de como serei vista, no futuro, pelos outros professores, gestores e pais. Já ouvi comentários do tipo que a professora do ano anterior tinha que ter ensinado tal conteúdo e não fez. (Elisa)

Estou com uma sala de $3^{\circ}$. ano, é o final do ciclo de alfabetização. Nesse ano o aluno pode ou não reprovar, isso gerou uma maior responsabilidade quanto a fazer com que as crianças aprendam e dessa maneira eu acabo ficando com aquela ânsia de ensinar, isto gera insegurança, medo de errar, também achei que seria mais fácil trabalhar com o material e utilizar metodologias de ensino. (Priscila)

As professoras destacaram dificuldades não só quanto à compreensão dos conteúdos, mas também à escolha da metodologia adequada. Nesse sentido, Barreto (2010) discorre que os conteúdos trabalhados nos anos iniciais têm sido considerados elementares e que pressupõe a discussão metodológica de como a criança aprende e já determina os próprios conteúdos a serem adotados. Isso pode fazer a diferença nas escolhas e na própria permanência na profissão. Trata-se do momento em que o professor tenta se inserir no grupo escolar e ser aceito, tanto pelos pares como pela comunidade, alunos, pais, supervisores etc.

Ao serem indagadas de como elas se viam na profissão nesse momento, revelaram seus dilemas vividos no seu dia a dia na profissão. Segundo Huberman (2013), ao mesmo tempo em que o professor tenta lidar com todos os eventuais problemas da sala de aula, assume, também, a postura de responsabilizar-se pelo processo de conduzir sua carreira, seus alunos, sua identidade profissional.

O dia a dia no contexto escolar é muito incerto, pois precisamos estar atentas para tudo o que acontece em nossa volta, como por exemplo: a administração do tempo pedagógico dos alunos, dos conteúdos, do meio educacional que estamos inseridas, dentre outras. Desta maneira, nos sentimos muito responsáveis por tudo, com isso, as decisões precisam ser rápidas e acertadas (Giovana).

[...] adentrar ao ambiente escolar é um desafio constante e cada dia aparece uma coisa nova como: alunos indisciplinados, alunos incluídos, atendimento aos pais, supervisora visitando a escola e até mesmo sua auto avaliação faz com que surjam dilemas constantes, vivendo desta maneira um período difícil de adaptação na carreira (Elisa). 
Em se tratando da fase do autoconhecimento e autoavaliação do seu trabalho, pode-se admitir que seja uma experiência saudável para a aquisição de novos conhecimentos e, principalmente, pelo aperfeiçoamento na profissão. Olhar a realidade de frente não é uma tarefa fácil, contudo viver idealizando uma sala de aula não ajudará o docente a superar os desafios cotidianos do contexto escolar e da sala de aula. O processo de inserção na carreira docente causa estranhamento, tendendo a processos de frustração ou satisfação no trabalho, mas a sua inserção é diferenciada e cada ambiente escolar proporciona vivências bem específicas, o que corrobora na construção da identidade profissional.

As docentes afirmaram que, ao adentrarem a sala de aula, há um sentimento de insegurança no sentido de não saber o que ensinar aos alunos, quais os saberes, os conteúdos a serem desenvolvidos, a maneira como abordar os temas, o planejamento das suas aulas, dificuldades quanto ao conteúdo pedagógico e de ensino, lidar com a diversidade dentro da sala etc.:

\begin{abstract}
Num primeiro momento tive "medo" e várias questões surgiram na minha cabeça, como: Será que vou dar conta de atingir os objetivos? Será que vou ser capaz de ensinar os alunos? Como devo agir com essas crianças? São tantas crianças sob minha responsabilidade e ainda não me sinto preparada porque esse ano que estou entrando no Ensino Fundamental, antes estava lecionando na educação infantil. [...]. As horas de estágios são poucas e eu ficava observando, olhando a professora, mas estar no lugar dela e atuando como tal é bem diferente. Então a formação na faculdade contribuiu de forma teórica, mas a prática não, eu acredito que estou aprendendo no dia a dia. [...]. Meu maior desafio foi desenvolver a metodologia para ensinar a criança, como fazer para os alunos aprenderem, porque na faculdade os professores me ensinaram os conteúdos, ou seja, o que eu ia ensinar, mas não como eu tenho de ensinar.... Eu tive e tenho que pesquisar sozinha (Giovana).
\end{abstract}

Para as docentes, essas questões não são abordadas de maneira satisfatória nas instituições de ensino superior, o que fez que elas buscassem em várias fontes as respostas para as suas perguntas, os seus conflitos. Obviamente que a formação inicial não vai dar conta de atender às questões referentes à sala de aula, pois é um ambiente envolto e propício a eventualidades, a heterogeneidades, ou seja, local de conflitos culturais (GARCIA, 1999).

No caso dos professores que ainda não possuem um referencial de sala de aula, a imagem construída acerca do ser professor durante a graduação entra em conflito com a realidade encontrada no ambiente escolar. Esse momento é muito delicado e chega a ser um choque, pois os modelos construídos são imediatamente colocados à prova e se percebe que o aluno real e a escola são mais complexos do que se imaginava.

A faculdade contribuiu para minha formação, mas não plenamente. Porque no dia a dia você tem que continuar estudando se preparando para cada aula e para tudo o que você vai realizar com a criança. Eu confesso que fiquei apreensiva de início, porque a gente não conclui a graduação tão preparada para a prática 
docente, e temos a noção que a prática está bem distante da teoria. Houve angústia, receio, um pouco até de insegurança. Certo dia eu disse: "Meu Deus! Estou parecendo uma barata tonta", você corre para cá, corre para lá, fica perdida sem saber exatamente o que fazer e as vezes ainda me pego nessa situação (risos) (Flávia).

As oito professoras entrevistadas responderam que, ao concluírem a graduação, não se sentiam preparadas para começar a exercer a docência e que houve um choque de realidade, com manifestação de sentimentos como medo, insegurança, ansiedade. Em vista desse dado, se coloca a necessidade de garantir espaços para reflexão e trocas de conhecimento entre gestores e seus pares de forma individual e coletiva, a fim de contribuir para o desenvolvimento profissional dos professores iniciantes.

Quando indagadas se elas tiveram algum tipo de apoio e/ou orientação no início da atuação docente, destacaram que foram bem acolhidas pelos gestores no ambiente da escola, receberam o material com os conteúdos que seriam desenvolvidos e algum tipo de orientação inicial, mas deixaram bem claro que sempre eram elas que procuravam os gestores quando surgia alguma dificuldade, sendo orientadas como deveriam proceder. Também esclareceram os momentos em que aconteciam as trocas de saberes entre os pares nas horas de estudo e na HTPC (Hora de Trabalho Pedagógico Coletivo).

Esses dados remeteram a pensar que são poucos os momentos que esses novatos recebem o suporte necessário e que isso retarda o processo da construção de suas identidades docentes. Ficou subentendido que seria interessante a proposição de formação continuada que corroborasse com esses docentes para que o início de carreira ocorresse sem muitos traumas. A literatura ainda indica que há certa escassez de ações no sentido de a escola apoiar os professores iniciantes, pois, de maneira geral, o início da carreira docente tem sido caracterizado por sentimentos de solidão, abandono e pelo isolamento, em virtude da ausência ou do pouco apoio institucional que é oferecido aos professores iniciantes (LIMA et al., 2015).

Nas entrevistas, quando se indagou sobre os aspectos que dificultavam o desempenho do seu trabalho, verificou-se que as questões relativas aos alunos, ou seja, indisciplina e desmotivação apareceram como fatores relevantes. Esses fatores deixaram explícitas as diferenças entre a representação do aluno ideal e o aluno real. Para Lima et al. (2015), o professor em sua formação idealiza um aluno voltado para a aprendizagem, obediente, respeitoso, acompanhado e apoiado por sua família. O relato da professora Flávia revelou esta afirmação:

A disciplina está difícil, às vezes, fico despontada, porque a escola deveria ser vista pelos pais não como um lugar para disciplinar, mas para ensinar e por mais que você passa para os alunos que eles estão aqui para aprender Matemática, Português, Geografia, os alunos nessa idade se agridem muito, se ofendem muito... Muitas vezes, você para a aula para chamar a atenção várias vezes, interrompe a explicação do conteúdo e isso atrapalha aqueles alunos que têm interesse em aprender (Flávia). 
Com base nessas considerações, questionou-se sobre as possíveis razões que levaram a essa mudança de como elas descreveram os alunos antes e após a sua inserção na carreira docente. Sobre isso, a professora Priscila relatou:

Muita coisa mudou. Na faculdade aprendemos sobre a "Pedagogia do Amor", a Aprendizagem Significativa, mas quando nos deparamos com a realidade temos crianças com muitas dificuldades de aprendizagens, outras com laudo médico, criança indisciplinada, criança que não quer fazer a lição, então é um choque de realidade e você indaga sobre o que aprendeu e o que está vivendo e pensa: como assim? Sente-se sozinha, senti muita insegurança, medo de errar (Priscila).

É notória a distância existente entre a formação inicial, muitas vezes idealizada nos cursos de formação e que depois é desvinculada do campo de trabalho real dos docentes, e a formação continuada, conforme relataram as professoras Cristina e Ana:

\begin{abstract}
A formação acadêmica não foi plena, posso dizer que foi bem parcial porque você estuda certos conteúdos na faculdade e percebe que a realidade é outra. Fica visível que há uma distância entre a teoria e a prática, os estágios contribuíram, de certa forma eles me deram base quanto à postura frente aos alunos e para analisar como eu desenvolveria certas atividades, mas a realidade é bem diferente. Quando assumi a sala de aula, meu primeiro sentimento foi o medo, medo de não dar conta da complexidade da docência (Cristina).
\end{abstract}

Posso dizer que a teoria é muito bonita e que temos que conhecê-la, mas na prática temos que adequá-la, pois na teoria tudo é muito lindo e tudo é muito certo, e a realidade dentro da sala de aula não é assim, sempre imaginamos durante a formação que teremos o domínio da classe, que os alunos aprenderão e serão atenciosos e interessados, mas não é bem assim (Ana).

Esses relatos convergiram para os estudos de Esteve (2006), quando afirma que a formação inicial do professor tem uma visão idealizada do ensino e que pouco corresponde à situação real da prática nas escolas e nas salas de aulas. É no decorrer do trabalho docente que os professores percebem a realidade e começam a diferenciar as expectativas iniciais, tanto quanto aos alunos e ao ambiente escolar, passando por um momento de transição, marcando sua passagem definitiva de estudante para professor, ou seja, da formação inicial para um complexo processo de transição do que seria o ideal e adequado para o real e possível no seu trabalho docente, configurando-se no choque de realidade (VEENMAN, 1984; HUBERMAN, 2013; TARDIF, 2002).

Porém, Garcia (1999) defende a ideia da necessidade do conhecimento das características socioeconômicas e culturais do local onde se ensina, assim como as pessoas a quem se ensina, sejam elementos obrigatórios dos saberes dos professores para a docência, o que poderia conferir subsídios necessários ao professor ao entrar no ambiente escolar.

Os espaços fundamentais de formação são as práticas de ensino e os estágios super- 
visionados, que podem proporcionar aos futuros professores o contato e experiência direta com a dinâmica do trabalho, sendo, portanto, uma tarefa essencial que compete aos cursos de formação inicial dos futuros professores. Todavia, apesar de sua relevância para a aprendizagem, os espaços de formação se mostram insuficientes no sentido de oferecer a compreensão da complexa prática no exercício docente (LEITE, 2011). Esses aspectos foram identificados quando as docentes foram indagadas sobre os estágios e como contribuíram para a sua formação.

Os estágios contribuíram parcialmente, não supriram todas as necessidades de formação porque na hora que você assume a classe é diferente a teoria da prática (Eduarda).

Os estágios contribuem para você ver um pouco da vivência da realidade da sala de aula porque você observa os procedimentos do professor mais experiente e dessa forma acaba vendo a postura dele (Maria).

Os relatos corroboraram as críticas apresentadas pela literatura, que apontam o modelo técnico e científico na maior parte dos estágios, que se reduz, às vezes, apenas às atividades de observação dos professores em sala de aula, seguido de relatório das situações consideradas e com supervisão insuficiente, sem uma análise crítica, fundamentada teoricamente e legitimada da realidade social (PIMENTA e LIMA, 2011; GATTI et al., 2011; LEITE, 2011).

As informações obtidas no estudo trouxeram dados no que tange à ausência de uma prática efetiva na formação inicial, o que constituiu uma lacuna percebida pelas professoras iniciantes na relação teoria e prática. Das oito professoras entrevistadas, seis não se sentiam preparadas para começar a exercer a docência e atribuíram isso à formação inicial, conforme apontado pelas professoras Priscila e Cristina.

Acho que faltou muita coisa ainda na minha formação acadêmica, minhas notas não eram ruins, eu imaginei que fosse mais fácil até trabalhar com o material didático, e não é, pois não adianta você chegar e ter uma "receitinha de bolo pronta", não é assim que funciona na escola. Você tem que estudar o tempo todo, pesquisar o tempo todo, você tem que dominar o assunto porque senão os alunos "te pegam" em situações que você não está preparada, você tem que estudar, pesquisar e pedir ajuda (Priscila).

A minha formação acadêmica não foi plena, foi bem parcial porque você recebe muita teoria na faculdade e na sala de aula é bem diferente, precisamos transformar tudo o que recebemos em prática (Cristina).

Tardif (2002, p. 86) descreve que "[...] muita coisa da profissão se aprende com a prática, pela experiência, tateando descobrindo, em suma, no próprio trabalho". Os conhecimentos dessas aprendizagens fazem parte dos saberes profissionais da docência, sendo denominado de "saberes experienciais". 
Cunha (2010) aponta que há um interesse significativo dos professores iniciantes em discutir suas práticas, repartir dificuldades e diferenças, compartilhar frustrações e sucessos, por ser um período em que os docentes estão buscando o seu estilo profissional, estabelecendo os valores que vão se constituindo numa marcante cultura do fazer pedagógico. A necessidade de explicitar e partilhar os problemas junto aos gestores é marcada como elemento relevante para as professoras, como fator de apoio e segurança para dar continuidade no fazer pedagógico.

\section{CONSTRUÇÃo DA PROFISSIONALIDAdE E IDENTIDADE DOCENTE}

A discussão sobre a construção da profissionalidade e identidade docente no início de carreira se caracteriza como a continuidade no seu processo de formação e se busca articular os conhecimentos adquiridos na formação inicial à sua prática, acionando seus conhecimentos específicos. Nesse momento, o professor novato começa a se relacionar com o outro, o que gera também identidades sociais, isto é, sentimentos de pertencer a um grupo em que passa a se identificar (SALES; OLIVEIRA, 2011).

Monteiro (2006) define que as especificidades em algumas profissões se apresentam de forma bem definida e sustentada pela valorização social, como no caso da Medicina, Engenharia, entre outras. Entretanto, na Educação, a especificidade não está clara, do ponto de vista social e também para a totalidade do grupo profissional.

O "ser" professor aparece diretamente ligado ao como fazer, à aplicação de técnicas e atividades, o que deixa implícito que todos podem ser professores, sem a necessidade de uma formação específica, ou seja, vivenciando o cotidiano na escola e compartilhando experiências são suficientes para se tornar professor. A especificidade e a ação docente se constituem na relação apropriação/objetivação e se diferenciam das demais práticas educativas que ocorrem na vida (MONTEIRO, 2006).

Para as professoras, a profissionalidade docente está vinculada, basicamente, à aquisição da experiência, expressando a meta de alcançar as experiências das professoras mais antigas de carreira.

\footnotetext{
Você termina a faculdade, mas ainda falta muito para uma formação plena, um bom exemplo é a dificuldade que temos em criar estratégias metodológicas para desenvolvermos os conteúdos, porque na faculdade aprendemos a teoria, mas ninguém ensina você dar aula realmente. Às vezes, temos simulações, mas a realidade é bem outra, os professores falam sobre as atividades algumas maneiras de ensinar, mas ainda fica distante da realidade (Elisa).
}

Eu sempre me preparo antes de vir para a escola para que tudo dê certo, me organizo com antecedência, pois estou começando na profissão e o meu trabalho está em andamento... Ainda quero ser vista como uma professora boa (risos) que as pessoas falem assim "essa dá conta da sala de aula", como algumas professoras mais antigas. (Risos) (Maria). 
Sempre observo as posturas das professoras mais experientes, sei que posso aprender com elas e peço ajuda quando preciso, a experiência na profissão vem com a prática (Eduarda).

Outra fala indicou a particularidade como saída, isto é, o professor fica sozinho dentro da sala de aula, construindo e articulando estratégias de como enfrentar dificuldades e desenvolver o seu trabalho.

Com certeza a busca para sanar as dificuldades é por conta própria, você tem que correr atrás, estudar, pesquisar, muitas vezes sinto-me muito sozinha para enfrentar esse desafio, mas penso que com o passar do tempo e as experiências vividas no dia a dia vou conseguindo (Eduarda).

É desse modo que muitas vezes o início da carreira docente tem ocorrido, de maneira solitária, dificultando a construção da especificidade da profissão, ou melhor, não possibilitando uma relação consciente com essa especificidade (DUARTE, 1992), o que impossibilita a qualidade do trabalho realizado e descaracteriza a atividade docente, dando abertura para o pensamento de que qualquer indivíduo poder realizá-la.

Falar em identidade docente se remete à reflexão do conceito sobre o seu trabalho, ou seja, se é bom ou não, e se consegue desenvolvê-lo de maneira plena e satisfatória, abrangendo os quesitos quanto aos conteúdos, posturas pedagógicas, ética, entre outros aspectos, bem como o que as professoras almejam estar ou alcançar no futuro. No decorrer da carreira, o docente pode mudar o modo de como enxerga seu trabalho e alterá-lo inúmeras vezes. Isto se deve ao fato de que tanto sua identidade pessoal quanto a profissional estão em constante mutação. Nesse contexto, a identidade é uma constante metamorfose porque provém da realidade e esta é sinônimo de movimento e de transformação (CIAMPA, 1984).

Outro aspecto interessante levantado durante as entrevistas está no fato de que as participantes relataram que refletiam sobre o seu trabalho com o propósito de melhorar seu desempenho no dia a dia e nas perspectivas futuras na profissão. As professoras, Maria e Cristina, enfatizaram isto em seus relatos:

Todos os dias quando chego em casa penso no meu dia de trabalho, como foi o desenvolvimento se houve rendimento por parte dos alunos e repenso nas atitudes tomadas e muitas vezes acho que acertei que errei, então penso que isso contribui para a caminhada que tenho pela frente na sala da aula (Cristina).

Gosto de avaliar o meu desempenho constantemente, ajuda a melhorar e me dá mais segurança, pois dessa forma reflito e posso mudar o que não gostei e melhorá-lo a cada dia (Maria).

É interessante analisar que as professoras fazem reflexão sobre suas práticas e olhar para o início da carreira, percebendo os seus avanços como algo que ocorreu em "certo caminhar", "uma suposta superação". Assim, "a identidade se concretiza na atividade social", 
inclusive nas relações de trabalho, refletindo a partir da construção do meu "eu" (passado, presente, futuro) e daquilo que sou, pois, como indivíduo, trago elementos que interiorizo, uma vez que "uma identidade que não se realiza na relação com o próximo é fictícia, é abstrata" (CIAMPA, 1984, p. 86).

Outro ponto a se destacar quando se trata da identidade profissional docente está relacionado à formação inicial que objetiva formar o professor para a função, pois, ao passar pela graduação, ele aprende diversos saberes referentes à sua profissão que darão base para a sua atuação. Pimenta e Lima (2011, p. 62) afirmam que "a identidade do professor é construída ao longo de sua trajetória como profissional do magistério. No entanto, é no processo de sua formação que são consolidadas as opções e intenções da profissão que o curso se propõe a legitimar".

É importante entender os elementos que vão, ao longo da carreira, influenciando na construção do "eu professor", na maneira como esse profissional se vê e se reconhece no seu trabalho. Ao tratar sobre a construção da identidade profissional, percebeu-se que as professoras relacionaram a construção da imagem que têm de si e sobre o seu trabalho, mas também por identidades delegadas por meio do outro, ou seja, pelos professores, gestores, alunos, pais, enfim, pela comunidade escolar onde convivem.

\footnotetext{
Quero ser uma professora competente que consegue passar para os meus alunos o conteúdo, eu quero ser reconhecida como aquela que consegue desenvolver os conteúdos de forma plena para os alunos e ainda desejo que a alguns anos possa passar na rua ser reconhecida pelos meus ex-alunos...Para mim, a identidade é como se fosse um degrau, você vai construindo devagarzinho e nunca vai acabar, você pode estar no final da carreira, mas nunca vai acabar, sempre vai aprender alguma coisa (Cristina).
}

Eu quero ser uma professora reconhecida pelo meu trabalho e pelo meu esforço sempre melhorando com pessoa e profissional, e que eu seja vista pela competência de ensinar (Eduarda).

Identificou-se, diante das explanações das professoras, que adjetivos pontuam se o professor é bom, ruim, eficaz, atencioso, técnico, reflexivo ou não, características de sua prática docente e se cria um perfil ideal ao professor, que assuma certas responsabilidades e papéis. De certa maneira, num primeiro momento, detectou-se que já existe uma identidade construída socialmente sobre a figura do docente e esta é a imagem que o novo professor quer assimilar e interiorizar para que se sinta de fato na profissão. Verificou-se que isso gera expectativas, pois o vir a ser professor é construído abrindo espaços e tecendo relações, enquanto que o reconhecimento do outro não é efetivado, o que induz o próprio indivíduo a não se considerar possuidor de determinada identidade. Essas preocupações diante do olhar do outro aparecem nos relatos de algumas docentes:

Os professores mais experientes ficam em dúvida se a gente vai dar conta da sala de aula, se a gente vai se enturmar com eles. É um olhar assim meio de avaliação, eles perguntam como a gente trabalha (Ana). 
Em relação aos professores mais experientes há um olhar crítico e não construtivo. Sinto mais ou menos assim, que para eles somos inexperientes e sabemos pouco ou quase nada.... Tem um monitoramento do trabalho... Quanto aos pais dos alunos, o primeiro contato que tive foi por causa de um acidente com uma menina que bateu o pezinho e eu pedi para ela ir colocar gelo e já era hora de ir embora.... Depois o pai veio dizendo que porque eu era professora nova não olhei direito... Mas eles não viram que eu tenho vinte e sete crianças na sala (Eduarda).

Esse processo gera angústia pelo fato de a construção da identidade profissional docente depender do julgamento e da aprovação ou reprovação do outro, não dependendo apenas dos julgamentos e afirmações próprias do indivíduo que está realizando a prática docente. Assim, a identidade profissional está vinculada às representações sociais e, para viver dentro de um grupo, os indivíduos acabam assimilando as formas de pertencimento no mesmo. Cada um busca o seu lugar para se instituir pessoal e profissionalmente.

\section{CONSIDERAÇões FINAIS}

A pesquisa teve como objetivo analisar e identificar a construção da identidade docente a partir do olhar do professor iniciante. Verificou-se que os principais problemas que afligem os docentes no momento da sua inserção na carreira docente são as dificuldades no desenvolvimento dos conteúdos curriculares, gestão em sala de aula, correlação entre teoria e prática e a escassez de apoio e experiência docente. Esses elementos ratificam que os primeiros anos de docência são difíceis, conflituosos, ou seja, é um momento de adaptação e conquistas pessoais e profissionais, provocando o choque da realidade que revela sentimentos de medo, angústia, sensação de incapacidade e a falta de preparação profissional.

No tocante à construção da identidade profissional docente, identificou-se que as professoras relacionaram essa construção a partir da imagem que elas tinham de si e sobre o seu trabalho, mas também por identidades delegadas por meio de outros, ou seja, pelos professores, gestores, alunos, pais, enfim, pela comunidade onde convivem e, principalmente, o reconhecimento de sua competência no ofício.

Contudo, a pesquisa revelou que as docentes confirmaram o seu desejo de prosseguir na carreira e seus argumentos apresentados se revelaram por razões de natureza implícita na docência, como, por exemplo, o gostar da profissão, o gostar de ensinar e o sentimento de realização profissional, mas também a de natureza explícita que, para elas, se tratam da responsabilidade de ensinar, o desenvolvimento do indivíduo e a formação de cidadãos.

Os achados da pesquisa apontaram que há necessidade de sérios e contínuos investimentos, em especial na valorização docente e na proposição de propostas de formação continuada. Para minorar o "choque com a realidade" e propiciar a construção de sua identidade profissional, o cenário ideal seria a implantação de programas de apoio com monitoramento por parte do setor público, com a finalidade de atender esses profissionais no momento de sua inserção no ambiente escolar, atendendo metas estabelecidas nos planos de educação. 


\section{REFERÊNCIAS}

BARRETO, Elba Siqueira de Sá. Trabalho docente e modelos de formação: velhos e novos embates e representações. Cadernos de Pesquisa, São Paulo, v. 40, n. 140, p. 427-443, mai./ago. 2010.

BOURDIEU, Pierre. A miséria do mundo, 3. ed. Petrópolis: Vozes, 1999.

CIAMPA Antônio da Costa. Identidade. In: CODO, W.; LANE, S. T. M. (Orgs.). Psicologia social: o homem em movimento. São Paulo: Brasiliense, 1984, p. 58-75.

CUNHA, Maria Isabel da. Trajetórias e lugares de formação da docência universitária: da perspectiva individual ao espaço institucional. Araraquara: JM Editora, 2010.

DUARTE, Newton. A formação do indivíduo e a objetivação do gênero humano (Categorias iniciais de uma reflexão sobre o processo de formação do indivíduo numa perspectiva histórico-social), 1992. Tese. (Doutorado em Educação) - Universidade Estadual de Campinas. Faculdade de Educação, Campinas, SP. Disponível em: $<$ http://www. bibliotecadigital.unicamp.br/document/?code=vtls000050761>. Acesso em: 15 mar. 2016.

ESTEVE, José M. Mudanças sociais e função docente. In: NÓVOA, A. (Org.). Profissão professor. Porto, PO: Ed. Porto, 2006.

FASSINA, Roseneide. Atratividade da carreira docente: Um estudo com pedagogas iniciantes. Dissertação (Mestrado em Educação), 2013. Universidade Católica de Santos. Santos, SP. Disponível em: <http://biblioteca.unisantos.br:8181/bitstream/tede/1201/2/Roseneide\%20Fassina.pdf $>$ Acesso em: 10 jun. 2016.

FERREIRA, Jacques de Lima. A complexa relação entre teoria e prática pedagógica na formação de professores. Formação de professores. Editora Vozes Limitada, 2014.

GARCIA, Carlos Marcelo. Formação de professores - para uma mudança educativa. Porto, PO: Ed. Porto, 1999.

GATTI, Bernadete Angelina et al. A atratividade da carreira docente no Brasil. Estudos e Pesquisas Educacionais, São Paulo, n. 1, p. 139-209, mai. 2011.

GIL, Antonio Carlos. Como elaborar projetos de pesquisa, 4. ed. São Paulo: Atlas, 2007.

HUBERMAN, Michael. O ciclo de vida profissional dos professores. In: NÖVOA, António (Org.). Vidas de professores, 2. ed. Porto, Portugal: Porto Editora, 2013, p. 31-61.

LAPO, Flavinês Rebolo; BUENO, Belmira Oliveira. Professores, desencanto com a pro- 
fissão e abandono do magistério. Cadernos de Pesquisa, São Paulo, n. 118, p. 65-88, mar. 2003.

LEITE, Yoshie Ussami Ferrari. O lugar das práticas pedagógicas na formação inicial de professores, 2011, 87s. Tese (Livre Docência) - Faculdade de Ciências e Tecnologia, Universidade Estadual Paulista, Presidente Prudente, SP. Disponível em: <http://repositorio. unesp.br/bitstream/handle/11449/109193/ISBN9788579832178.pdf?sequence=1>. Acesso em: 15 abr. 2016.

LEONE, Naiara Mendonça. Necessidades formativas dos professores dos anos iniciais na sua inserção no exercício da docência, 2011. Dissertação (Mestrado em Educação) Faculdade de Ciências e Tecnologia da Universidade Estadual Paulista, Presidente Prudente, SP, 2011. Disponível em: <http://repositorio.unesp.br/bitstream/handle/11449/90200/ leone_nm_me_prud.pdf?sequence=1\&isAllowed=y>. Acesso em: 10 abr. 2016.

LIMA, Francielly Dornelas C., OLIVEIRA Ana Clara Lacerda de, ARAÚJO Tamires Sousa e MIRANDA, Gilberto José. O choque com a realidade: dormi contador e acordei professor. REICE. Revista Iberoamericana sobre Calidad, Eficacia y Cambio en Educación, v. 13, n. 1, 2015. Disponível em: < https://repositorio.uam.es/bitstream/handle/10486/666595/REICE_13_1_4.pdf?sequence=1>. Acesso em: 10 abr. 2016.

LOTUMOLO, Thais Elena. Professores Iniciantes: Como Compreendem o seu Trabalho? 108s. Dissertação (Mestrado em Educação) - Faculdade????, Universidade Federal de São Carlos - UFSCAR, São Carlos, SP, 2014. Disponível em: <https://repositorio.ufscar.br/bitstream/handle/ufscar/2697/5778.pdf?sequence=1\&isAllowed=y $>$ Acesso em: 10 abr. 2016.

LUDKE, Menga, ANDRE, Marli Eliza Dalmazo Afonso de. Pesquisa em educação: abordagens qualitativas, 2. ed. Rio de Janeiro: E. P. U., 2013.

MARIANO, André Luiz Sena. A construção do início da docência: um olhar a partir das produções da ANPEd e do ENDIPE, 2006a, 156s. Dissertação (Mestrado em Educação) Centro de Educação e Ciências Humanas, Universidade Federal de São Carlos, São Carlos, SP, 2006. Disponível em: <https://repositorio.ufscar.br/bitstream/handle/ufscar/2796/DissALSM.pdf?sequence=1\&isAllowed=y >. Acesso em: 15 abr. 2016.

MONTEIRO, Hilda Maria. Eu não sabia o que agora sei...: tornando públicas as minhas histórias secretas. In: LIMA, Emília Freitas de (Org.). Sobrevivências no início da docência. Brasília: Líber Livro, 2006, p. 27-38.

PAPI, Silmara de Oliveira Gomes. Professoras iniciantes: formação, experiência e desenvolvimento profissional. Pro-Posições, v. 25, n. 1, p. 199-218, 2014. Disponível em: $<$ http://www.scielo.br/pdf/pp/v25n1/v25n1a11.pdf>. Acesso em: 20 abr. 2016. 
PIMENTA, Selma Garrido; LIMA, Maria Socorro. Estágio e Docência. São Paulo: Editora Cortez, 2011.

ROLDÃO, Maria do Céu. Função docente: natureza e construção do conhecimento Profissional. Revista Brasileira de Educação, Rio de Janeiro, v. 12, n. 34, p. 94-103, jan./abr. 2007.

SACRISTÁN, José Gimeno. O currículo uma reflexão sobre a prática. Porto Alegre: Artmed, 1998.

SALES, Adriane de Castro Menezes; OLIVEIRA, Edna Maria Querido de. Escolha da carreira e processo de construção da identidade profissional docente, 2011. Disponível em: http://www.scielo.br/pdf/edur/v27n3/v27n3a10. Acesso em: 15 jul. 2016.

SANTOS, Maria de Cássia dos. A construção de identidade profissional docente: relatos de Histórias de Vida, 2012. Dissertação (Mestrado em Ciência da Educação). Universidade Lusófona de Humanidades e Tecnologias, 2012. Disponível em: http://recil.grupolusofona. pt/handle/10437/2801. Acesso em: 10 abr. 2016.

TARDIF, Maurice. Saberes docentes e formação profissional, 2. ed. Petrópolis: Vozes, 2002.

VEENMAN, Simon. Perceived Problems of Beginning Teachers. Review of Educational Research [S.I.], v. 54, n. 2, p. 143-178, 1984.

VEIGA, Ilma Passos Alencastro. A aventura de formar professores. Educar em Revista, 2013. Disponível em: $<$ http://www.scielo.br/scielo.php?script=sci_arttext\&pid =S0104-40602013000400020> Acesso em: 15 mai. 2016.

Artigo elaborado a partir da dissertação de Mestrado: A inserção do professor nos anos iniciais do ensino fundamental: a construção de sua identidade profissional - orientadora: Dra. Raimunda Abou Gebran, doutora em Educação pela UNICAMP e professora titular Programa de Pós-Graduação em Educação da Universidade do Oeste Paulista/UNOESTE.

\section{Tânia Cristina Silva Pessoa}

Mestre em Educação pela Universidade do Oeste Paulista (UNOESTE/ 2016). Pós -Graduada em Interdisciplinaridade e Transversalidade em Educação: um projeto em construção; (Unoeste) e Psicopedagogia Institucional; pela EDUCON - Sociedade de Educação Continuada, possuir MBA em Docência no Nível Superior; pelo Senac- P.Pte; Graduada 
em Letras e Pedagogia pela UNOESTE (Universidade do Oeste Paulista- P.Pte/SP). Atualmente exerce a função de Supervisora de Ensino, na cidade de Rancharia-SP; Leciona na Faculdade Ranchariense no Curso de Pedagogia

\section{Raimunda Abou Gebran}

Graduação em Geografia e Pedagogia pela UNESP. Mestrado e Doutorado em Educação pela Universidade Estadual de Campinas. Atualmente é professor titular do Programa de Pós-Graduação em Educação (Mestrado) da Universidade do Oeste Paulista. Líder do Grupo de Pesquisa Contexto Escolar e Processo de Ensino Aprendizagem - ações e interações (UNOESTE). Membro do Grupo de Pesquisa Formação de Professores e Práticas de Ensino na Educação Básica e Superior da Universidade Estadual Paulista Júlio de Mesquita Filho (UNESP). Tem experiência na área de Educação, com ênfase em metodologia do ensino, atuando principalmente nos seguintes temas: ação docente, construção do conhecimento, ensino fundamental, ensino-aprendizagem e ensino de geografia

Submetido em: 5-4-2018

Aceito em: 25-6-2018 